\title{
Clinical and radiographic outcomes of hybrid graft in patients with Modic changes undergoing transforaminal lumbar interbody fusion
}

\author{
Jiaxun Jiao ${ }^{1,2,3}$, Jiaqi Li $\mathrm{Li}^{1,3}$, Yun Luo ${ }^{1,3}$ and Wei Zhang ${ }^{1,3^{*}}$
}

\begin{abstract}
Background: This retrospective study aimed to analyze the influence of Modic changes (MCs) on the clinical and radiographic outcomes of transforaminal lumbar interbody fusion with hybrid graft.

Methods: Clinical data of 89 patients with Modic changes who underwent single-segment transforaminal lumbar interbody fusion between January 2015 and January 2019 at our institution were analyzed. Patients were divided into three groups: the MCs-0 group (no endplate changes; used as the control group), the MCs-1 group, and the MCs-2 group. Clinical and radiological parameters were compared between the three groups.

Results: There were no significant between-group differences in age $(P=0.216)$, sex $(P=0.903)$, body mass index $(P=0.805)$, smoking $(P=0.722)$, diagnosis $(P=0.758)$, surgical level $(P=0.760)$, blood loss $(P=0.172)$, operative time $(P=0.236)$, or follow-up $(P=0.372)$. Serum $C$-reactive protein level and erythrocyte sedimentation rate in the MCs-1 and MCs-2 groups were significantly higher than those in the MCs-0 group on the third and seventh days ( $P$ $<0.05)$. Postoperative radiographic parameters were significantly higher than preoperative parameters in all 3 groups $(P<0.05)$. Visual analog scale scores for low back pain in the MCs-0 and MCs-2 groups were significantly different from those in the MCs-1 group $(P<0.05)$. However, there were no significant between-group differences with respect to Oswestry Disability Index scores or visual analog scale scores for leg pain.

Conclusion: In this study, Modic changes had no impact on fusion rates and clinical outcomes of transforaminal lumbar interbody fusion with hybrid graft (autologous local bone graft plus allogeneic freeze-dried bone graft). However, MCs-1 increased the risk of cage subsidence and showed superior outcomes in terms of visual analog scale scores for low back pain.
\end{abstract}

Keywords: Modic changes, Transforaminal lumbar interbody fusion, Autologous local bone graft, Allogeneic freezedried bone graft, Fusion, Outcomes

\footnotetext{
*Correspondence: zwhbyk@163.com

${ }^{1}$ Department of Spinal Surgery, The Third Hospital of Hebei Medical

University, Shijiazhuang 050051, People's Republic of China

${ }^{3}$ The Key Laboratory of Orthopedic Biomechanics of Hebei Province, The Third Hospital of Hebei Medical University, Shijiazhuang 050051, People's Republic of China

Full list of author information is available at the end of the article
}

(c) The Author(s). 2021, corrected publication 2022. Open Access This article is licensed under a Creative Commons Attribution 4.0 International License, which permits use, sharing, adaptation, distribution and reproduction in any medium or format, as long as you give appropriate credit to the original author(s) and the source, provide a link to the Creative Commons licence, and indicate if changes were made. The images or other third party material in this article are included in the article's Creative Commons licence, unless indicated otherwise in a credit line to the material. If material is not included in the article's Creative Commons licence and your intended use is not permitted by statutory regulation or exceeds the permitted use, you will need to obtain permission directly from the copyright holder. To view a copy of this licence, visit http://creativecommons.org/licenses/by/4.0/ The Creative Commons Public Domain Dedication waiver (http://creativecommons.org/publicdomain/zero/1.0/) applies to the data made available in this article, unless otherwise stated in a credit line to the data. 


\section{Background}

Transforaminal lumbar interbody fusion (TLIF) is a widely used procedure for treatment of degenerative lumbar spine disease. During the surgery, implantation of an intervertebral cage and autologous bone graft help restore the intervertebral height and promote fusion [1-3]. Bone graft material is one of the main determinants of intervertebral fusion. The common sources of bone graft used for TLIF include autologous iliac graft, autologous local bone graft, and allograft. Each bone graft material has its advantages and disadvantages. The use of autologous iliac graft or local bone graft is associated with reasonable fusion rate and does not entail the risk of rejection; however, availability of a limited amount of bone graft and increase in the postoperative recovery time are disadvantages. The use of allograft does not entail the problems of limited autologous bone supply and invasive bone retrieval. However, the treatment cost is typically high, and allografts are prone to rejection, osteolysis, and resorption [4-6].

Cage subsidence (CS) is one of the complications that results in gradual loss of disc height (DH) and segmental lordosis (SL). Previous studies have suggested that CS is associated with osteoporosis, excessive distraction of the intervertebral space, and damage to the endplate [7-10]. Modic changes (MCs) in the lumbar endplate and subendplate bones on magnetic resonance imaging (MRI) images are classified into three types: MCs-1 is considered as the inflammatory phase or edema phase; MCs-2 is considered as the fatty phase or yellow marrow phase; MCs-3 is considered as the osteosclerosis phase. Previous studies have shown that MCs are one of the reasons for low back pain and are closely related to lumbar degeneration. There is no clear consensus as to whether MCs affect the fusion. Some studies showed that MCs inhibit the process of fusion, as fusion rate after posterior interbody fusion was lower in patients with MCs. In contrast, other studies have shown good fusion results in patients with MCs [11-15].

MCs reflect an inflammatory dysmyelopoiesis which can induce biological and/or microstructural changes in the subchondral trabecular bone and affect the stable contact between the graft and the endplate $[16,17]$. It is not clear whether the bone graft material affects intervertebral fusion and increases the risk of CS, especially when MCs are present in the endplate. We hypothesized that MCs affect the mechanical strength or biological properties of the subchondral bone and affect the fusion rate, especially after use of allograft during the surgery. In this retrospective study, we aimed to analyze the influence of MCs on the clinical and radiographic outcomes of TLIF with hybrid graft.

\section{Methods}

Clinical data of 89 patients who underwent singlesegment TLIF at the Third Hospital of Hebei Medical University between January 2015 and January 2019 were retrospectively analyzed. This study was approved by the Institutional Review Board of the authors' institution. Written informed consent was obtained from all patients, and all clinical procedures were carried out according to the principles in the Declaration of Helsinki. Inclusion criteria were (1) patients with lumbar disc herniation (LDH), lumbar spinal stenosis (LSS), or lumbar spondylolisthesis (LS) who had significant symptoms and showed no response to at least 3 months of standardized conservative treatment; (2) availability of complete clinical and imaging data (x-ray examination, MRI, and CT); (3) single-segment TLIF with a single polymer polyetheretherketone (PEEK) cage; and (4) postoperative follow-up $>1$ year.

Exclusion criteria were (1) presence of fracture, tuberculosis, or tumor; (2) intraoperative endplate damage or immediate postoperative radiographs revealing fusion settling; (3) previous history of surgery or trauma; (4) combined congenital or developmental deformities; and (5) osteoporosis (bone mineral density (BMD) $T$ value $\leq$ $-2.5)$.

To assess the impact of MCs on the clinical outcomes of TLIF, patients were divided into three groups: the MCs-0 group (no endplate changes; used as the control group) (Fig. 1), the MCs-1 group (Fig. 2), and the MCs-2 group (Fig. 3). MCs-3 was not seen in the present study.

\section{Surgery}

A conventional posterior median approach was used. The anatomical structures of the vertebral body and articular processes of the operated segment were exposed. The nail entry point was determined, and the pedicle screw was accurately placed. The more symptomatic side was used as the TLIF access side. Laminectomy and facetectomy were performed to expose the decompressed side. The intervertebral disc was dissected. The upper and lower endplates were also cleaned with a spatula, and the cartilage endplates were scraped to allow a small amount of blood to ooze from the bony endplates. After discectomy and endplate preparation, autologous local bone graft and allogeneic freeze-dried bone graft were filled into the intervertebral space. One PEEK cage of the appropriate size packed with autologous local bone graft was placed in the intervertebral area. The connecting rod was installed and held under pressure, followed by suture of the incision. Antibiotics were administered preoperatively and for $24 \mathrm{~h}$ postoperatively to prevent infection. The drainage was removed after the flow was less than $50 \mathrm{~mL} / 24 \mathrm{~h}$. During the period of bed rest, straight leg elevation functional 


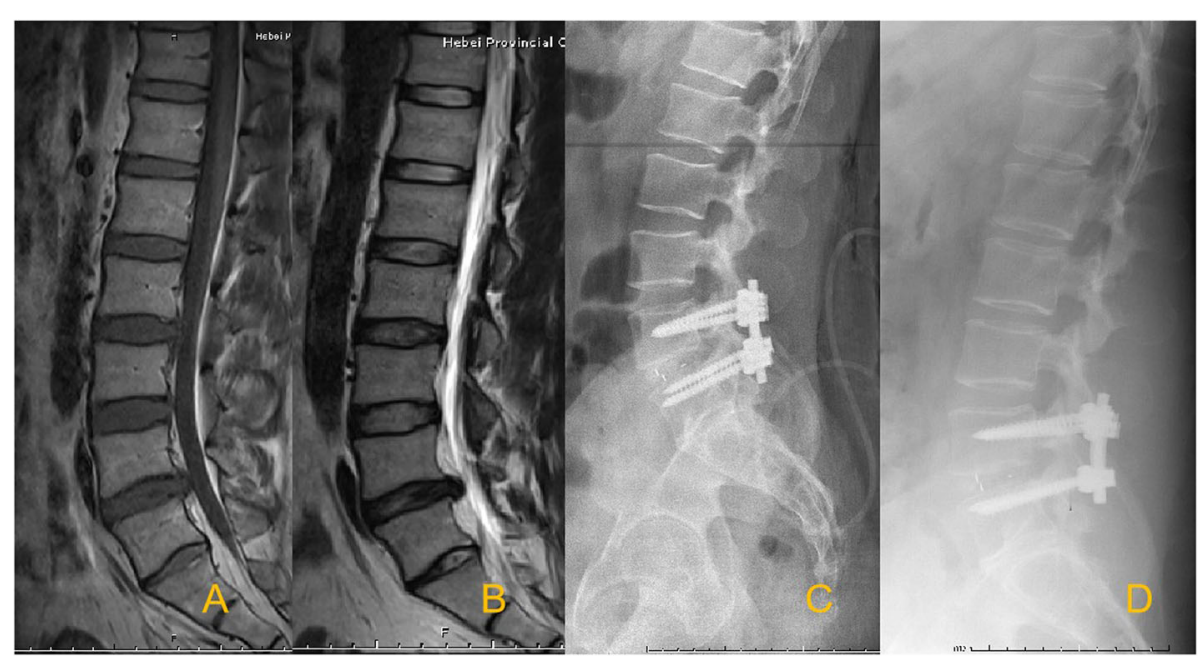

Fig. 1 Sagittal T1-weighted (A) and T2-weighted (B) magnetic resonance images demonstrate L4-L5 lumbar disc herniation with MCs-0 signs. Postoperative radiographs $(\mathbf{C})$ at the most recent follow-up confirming the solid fusion (D)

exercises were performed, and the brace was used to protect the movement on the ground on the third day after surgery.

\section{Assessment parameters and measurements}

Preoperative and postoperative data were recorded. For patients with longer follow-up, the most recent evaluation was included in the analysis. Preoperative MRI images were observed to determine the presence of MCs in the endplate. All MRI images were observed by two orthopedic surgeons who were blinded to the clinical outcomes. Disagreements, if any, were resolved by consensus.
The serum level of C-reactive protein (CRP) and erythrocyte sedimentation rate (ESR) were evaluated before surgery and on days $1,3,7,15$, and 21 postoperatively. The immunoturbidimetric method was used to determine the CRP level $(<10 \mathrm{mg} / \mathrm{L})$. The modified Westergren method was used to measure the ESR $(<15$ $\mathrm{mm} / \mathrm{h}$ ). The demographic data included age, sex, body mass index (BMI), surgical level, and complications. Radiographic parameters included lumbar lordosis (LL), which was measured as the angle between the upper endplate of L1 and the upper endplate of S1. Segmental lordosis (SL) was measured as the angle subtended by the superior endplate line of the caudal vertebral body

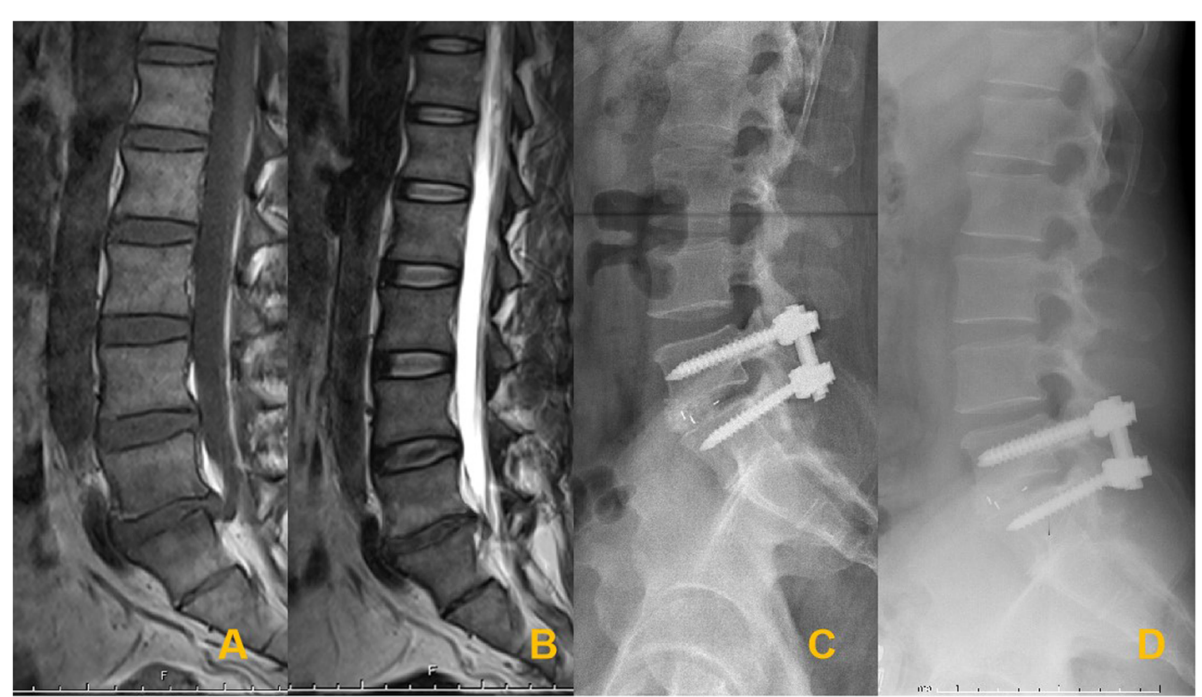

Fig. 2 Sagittal T1-weighted (A) and T2-weighted (B) magnetic resonance images demonstrate L5-S1 lumbar disc herniation with MCs-1 signs. Postoperative radiographs $(\mathbf{C})$ at the most recent follow-up confirming the solid fusion (D) 


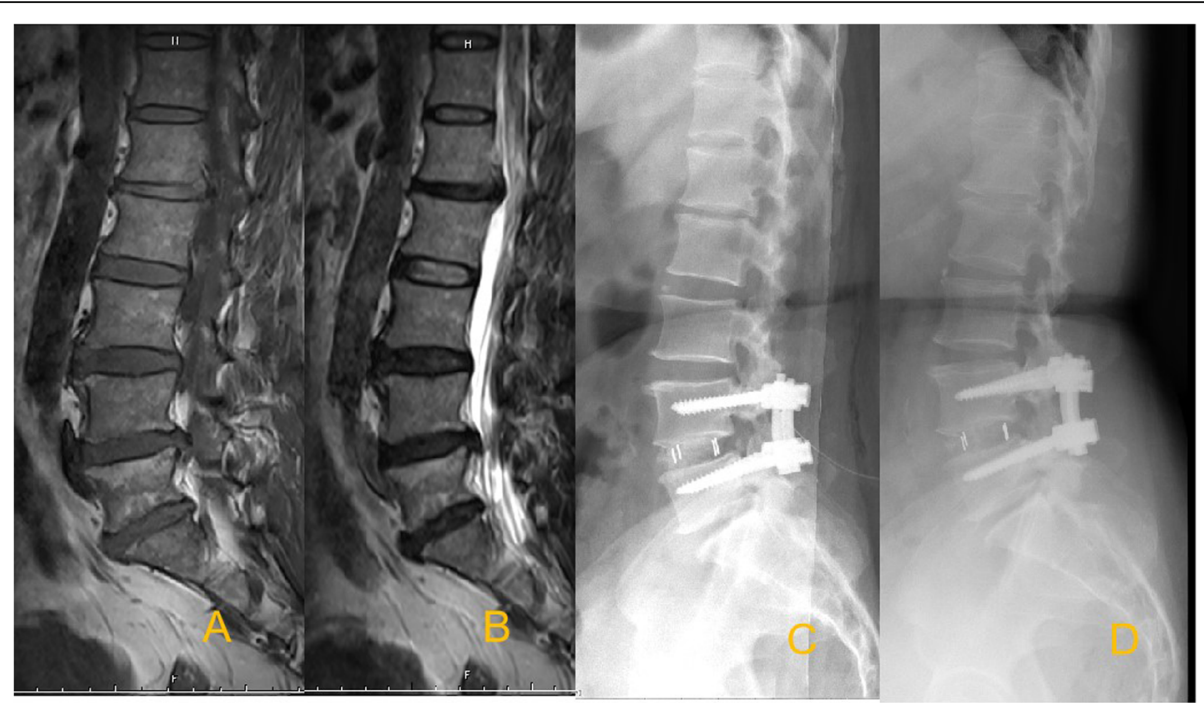

Fig. 3 Sagittal T1-weighted (A) and T2-weighted (B) magnetic resonance images demonstrate L4-L5 lumbar disc herniation with MCs-2 signs. Postoperative radiographs $(\mathbf{C})$ at the most recent follow-up confirming the solid fusion (D)

and the inferior endplate line of the cephalad vertebral body. DH was defined as an average of the anterior and posterior margins of the intervertebral space (Fig. 4). CS was evaluated using postoperative images and described as sinking of the cage into the adjacent vertebral body by $>2 \mathrm{~mm}$. Solid fusion was considered to be achieved in the presence of bridging bone between the endplates of the cephalad and caudal vertebral bodies (Fig. 5). Fusion was divided into four grades [18]. Patients with grades of 1 or 2 were considered to have achieved fusion (grade 1, fused with remodeling and trabeculae crossing vertebral endplate; grade 2, graft intact with no radiolucency but not fully remodeled; grade 3, graft intact, radiolucency present at top and bottom of the graft; and grade 4, collapse or resorption of the graft).

\section{Quality of life assessment}

Questionnaires were administered to patients before surgery, at 3 months after surgery, and at the final followup to evaluate quality of life. The Oswestry Disability Index (ODI) scale was used to evaluate clinical efficacy, and visual analog scale (VAS) was used for assessment of low back pain and leg pain.

\section{Statistical methods}

SPSS 21.0 software was used for statistical analyses. Continuous variables are presented as mean \pm standard deviation. The paired $t$ test was used to compare the preoperative and postoperative parameters. Repeatedmeasures analysis was used for CRP and ESR levels and Student-Newman-Keuls test was used for group-togroup comparisons. Comparison between the three different groups was conducted using one-way analysis of variance and post hoc Student-Newman-Keuls test. Two-sided $P$ values $<0.05$ were considered indicative of statistical significance.

\section{Results}

There were 38 patients in the MCs- 0 group, 20 patients in the MCs-1 group, and 31 patients in the MCs-2 group. All patients in this study experienced significant relief in back and leg pain. No serious complications, such as infection or nerve injury, were observed in any of the three groups. None of the patients required additional surgery because of recurrent or residual back and leg pain. There were no significant differences between the 3 groups with respect to preoperative demographic factors, including age $(P=0.216)$, sex $(P=0.903)$, BMI $(P=0.805)$, smoking $(P=0.722)$, diagnosis $(P=0.758)$, surgical level $(P=0.760)$, blood loss $(P=0.172)$, operative time $(P=0.236)$, or duration of follow-up $(P=$ 0.372) (Table 1).

All patients had achieved fusion (67 cases achieved grade I fusion, and 22 cases achieved grade II fusion). No cases of grade III or IV fusion were observed. CS was detected in 8 cases $(40.0 \%)$ in the MCs- 1 group, 7 cases (22.6\%) in the MCs-2 group, and in 6 cases $(15.8 \%)$ in the MCs-0 group. The percentage of patients in the MCs-1 group who experienced CS was significantly higher than that in the MCs- 0 and MCs- 2 groups $(P<0.05)$.

The CRP and ESR values increased in all three groups. The peak CRP level was reached on the third day, and the peak ESR level was reached on the seventh day after TLIF. The CRP and ESR levels decreased after reaching their peak values. The CRP and ESR levels in the MCs-1 


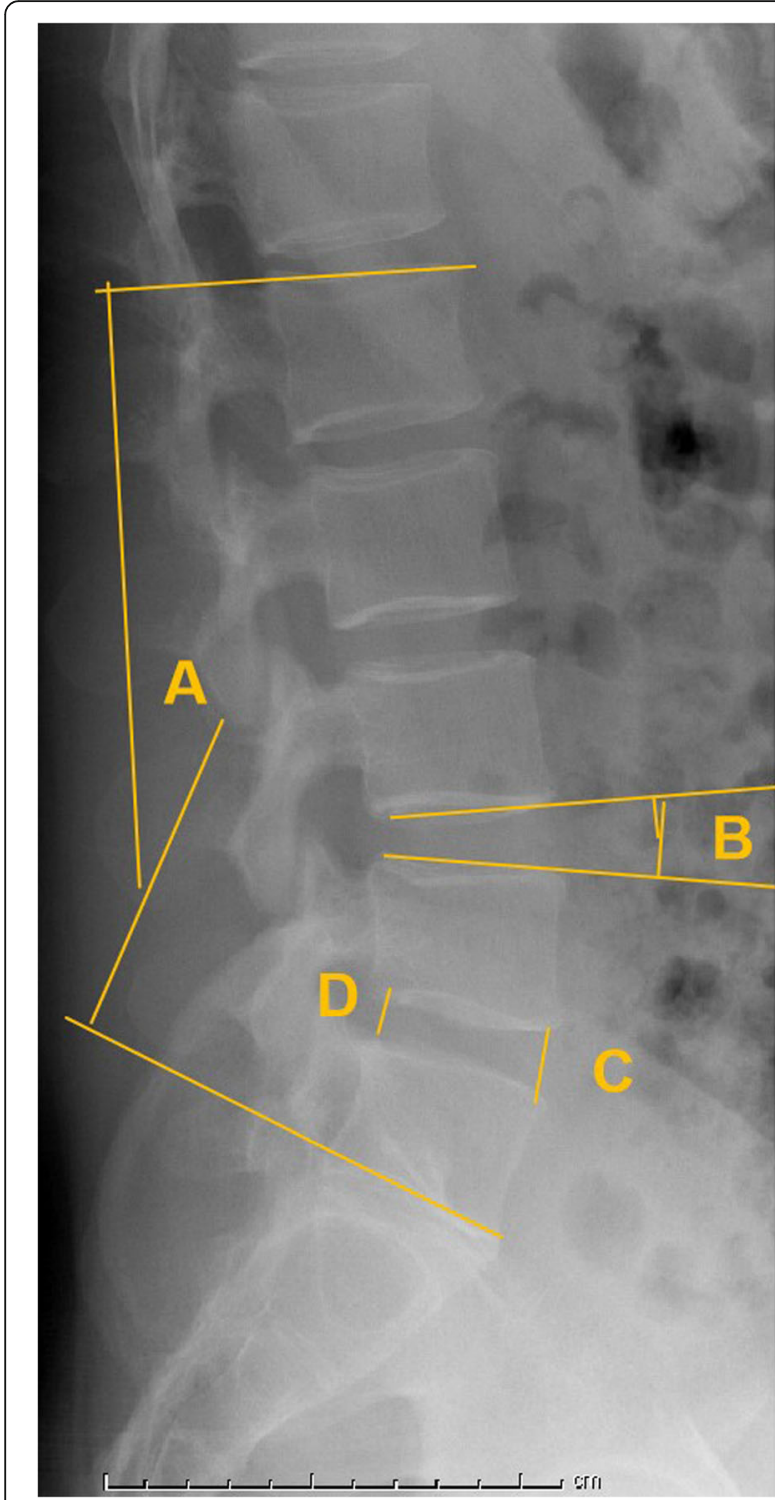

Fig. 4 Lumbar lordosis (A): the angle between the upper endplate of $\mathrm{L} 1$ and the upper endplate of S1. Segmental lordosis (B): the angle subtended by the superior endplate line of the caudal vertebral body and the inferior endplate line of the cephalad vertebral body. Disc height: average of the anterior $(\mathbf{C})$ and posterior (D) margins of the intervertebral space

and MCs-2 groups were significantly higher than those in the MCs- 0 group on the third and seventh days $(P<$ $0.05)$. However, there were no significant differences in CRP and ESR levels between the MCs-1 and MCs-2 groups after TLIF $(P>0.05)$ (Table 2$)$.

The immediate postoperative $\mathrm{DH}, \mathrm{LL}$, and SL were significantly higher than those measured preoperatively in the 3 groups $(P<0.05)$. The DH increased significantly to $11.5 \pm 1.9 \mathrm{~mm}, 11.3 \pm 2.1 \mathrm{~mm}$, and $11.6 \pm 1.7$ $\mathrm{mm}$ postoperatively and was maintained at $10.9 \pm 2.1$ $\mathrm{mm}, 9.7 \pm 1.5 \mathrm{~mm}$, and $9.8 \pm 1.6 \mathrm{~mm}$ at the most recent

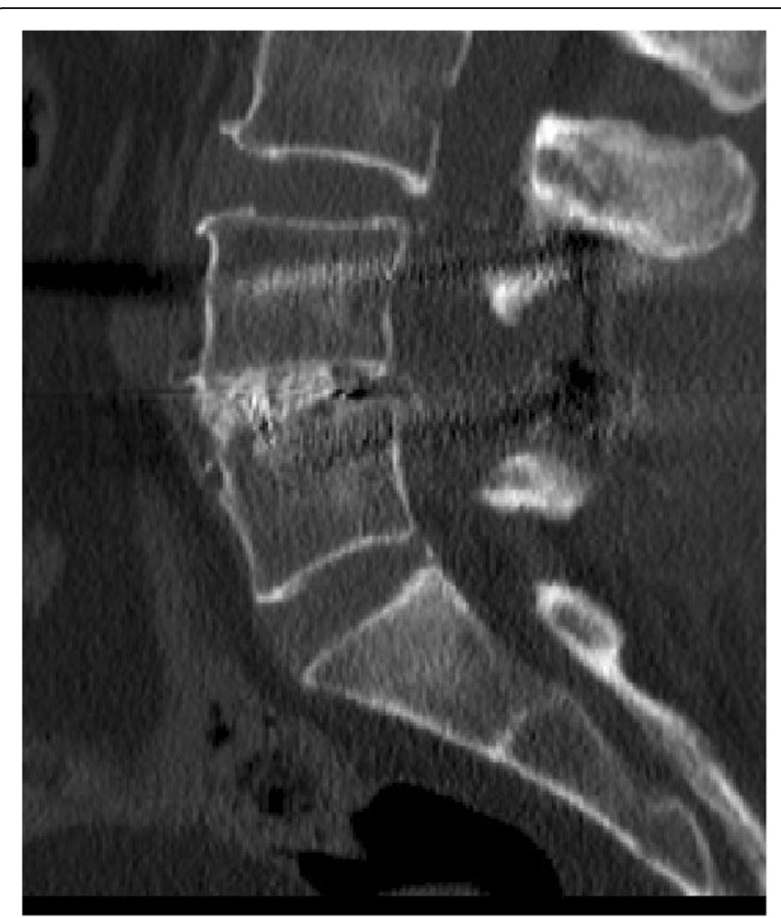

Fig. 5 Solid fusion was considered to be achieved in the presence of bridging bone between the endplates of the cephalad and caudal vertebral bodies

follow-up in the MCs-0, MCs- 1 , and MCs-2 groups, respectively. The LL increased significantly to $54.3 \pm 10.8^{\circ}$, $55.8 \pm 11.3^{\circ}$, and $54.5 \pm 13.6^{\circ}$ postoperatively and was maintained at $53.5 \pm 11.6^{\circ}, 52.8 \pm 13.3^{\circ}$, and $52.8 \pm 15.1^{\circ}$ at the most recent follow-up in the MCs-0, MCs-1, and MCs-2 groups, respectively. The SL increased significantly to $18.9 \pm 6.3^{\circ}, 18.2 \pm 7.8^{\circ}$, and $18.5 \pm 8.3^{\circ}$ postoperatively, and was maintained at $18.1 \pm 7.5^{\circ}, 17.3 \pm 6.7^{\circ}$, and $17.8 \pm 8.7^{\circ}$ at the most recent follow-up in the MCs-0, MCs- 1 , and MCs-2 groups, respectively. No significant between-group differences were observed with respect to the postoperative DH, LL, and SL or at the most recent follow-up $(P>0.05)$ (Table 3$)$.

The ODI and VAS scores for low back pain and leg pain showed significant improvement after surgery in all 3 groups $(P<0.05)$. VAS scores for low back pain in both the MCs-0 and MCs-2 groups were significantly different from those in the MCs-1 group $(P<$ 0.05). The VAS scores for low back pain in the MCs2 group were slightly superior than those in the MCs-0 group; however, the between-group difference in this respect was not statistically significant $(P>$ 0.05). The ODI and VAS scores for leg pain had significantly improved at the last follow-up $(P<0.05)$. However, the ODI and VAS scores for leg pain showed no significant difference among the 3 groups $(P>0.05)$ (Table 4$)$. 
Table 1 Demographic data of patients in the 3 groups

\begin{tabular}{|c|c|c|c|c|}
\hline & MCs-0 group & MCs-1 group & MCs-2 group & $P$ value \\
\hline Age (years) & $55.6 \pm 8.6$ & $56.3 \pm 11.2$ & $58.3 \pm 7.8$ & 0.216 \\
\hline Gender (M/F) & $18 / 20$ & $9 / 11$ & $13 / 18$ & 0.903 \\
\hline BMI & $25.7 \pm 8.5$ & $26.7 \pm 7.8$ & $26.3 \pm 8.1$ & 0.805 \\
\hline Smoking & $13 / 25$ & 9/11 & $12 / 19$ & 0.722 \\
\hline Diagnosis & & & & 0.758 \\
\hline LDH & 15 & 11 & 13 & \\
\hline LSS & 13 & 5 & 12 & \\
\hline LS & 10 & 4 & 6 & \\
\hline Surgical level & & & & 0.760 \\
\hline L3-L4 & 6 & 1 & 5 & \\
\hline L4-L5 & 20 & 12 & 16 & \\
\hline L5-S1 & 12 & 7 & 10 & \\
\hline \multicolumn{5}{|l|}{ Cage subsidence } \\
\hline Subsidence & 6 & 8 & 7 & 0.117 \\
\hline No subsidence & 32 & 12 & 24 & \\
\hline Blood Loss (mL) & $116.6 \pm 21.1$ & $120.8 \pm 23.9$ & $119.2 \pm 19.5$ & 0.172 \\
\hline Operative time (min) & $79.6 \pm 17.5$ & $82.3 \pm 20.8$ & $80.5 \pm 21.2$ & 0.236 \\
\hline Follow up (month) & $23.3 \pm 3.8$ & $22.4 \pm 2.5$ & $24.3 \pm 5.6$ & 0.372 \\
\hline
\end{tabular}

\section{Discussion}

Spinal fusion surgery is one of the effective methods for the treatment of lumbar degenerative diseases. The advances in surgical techniques have helped reduce the invasiveness of the posterior decompression approach [19-21]. The bone graft material is an important factor that affects spinal fusion. The ideal bone graft material should have the following characteristics: good biodegradability and biocompatibility, no or low immunogenicity, osteoconductivity and osteoinductivity, mechanical tolerance, ease of processing into various shapes and sizes, three-dimensional structure, and high porosity, which facilitates the placement and adhesion of various growth factors. The primary sources of bone graft for intervertebral fusion are autologous iliac bone graft, autologous local bone graft, and allogeneic bone graft [22-24].

The autologous local bone graft is removed during posterior decompression, which comprises of mostly cortical bone and partially cancellous bone. The autologous local bone graft enables faster healing and is less likely to collapse. However, it has a limited bone volume and lower bone quality (very little cancellous bone) compared with the autologous iliac bone graft (large bone volume and better bone quality) [25-27]. Autologous iliac bone graft is still the preferred bone graft material when the bone volume obtained from decompression cannot meet the demand for intervertebral bone

Table 2 CRP and ESR values before surgery through postoperative day 21

\begin{tabular}{|c|c|c|c|c|c|c|}
\hline & \multirow[t]{2}{*}{ Preoperative } & \multicolumn{5}{|c|}{ Postoperative } \\
\hline & & Day 1 & Day 3 & Day 7 & Day 15 & Day 21 \\
\hline \multicolumn{7}{|l|}{ CRP level, mg/L } \\
\hline MCs-0 group & $1.9 \pm 0.8$ & $20.3 \pm 5.5^{*}$ & $58.2 \pm 11.7^{*}$ & $23.8 \pm 9.7^{*}$ & $8.6 \pm 1.7^{*}$ & $2.3 \pm 1.9$ \\
\hline MCs-1 group & $2.2 \pm 1.1$ & $26.3 \pm 73^{*}$ & $66.3 \pm 15.2^{*}$ & $30.6 \pm 10.1^{*}$ & $10.7 \pm 2.3^{*}$ & $5.3 \pm 1.5$ \\
\hline MCs-2 group & $2.1 \pm 0.9$ & $24.8 \pm 8.6^{*}$ & $62.9 \pm 13.1^{*}$ & $27.3 \pm 8.2^{*}$ & $9.3 \pm 1.9^{*}$ & $3.6 \pm 2.1$ \\
\hline \multicolumn{7}{|l|}{$\mathrm{ESR}, \mathrm{mm} / \mathrm{h}$} \\
\hline MCs-0 group & $9.6 \pm 2.5$ & $19.5 \pm 2.3^{*}$ & $39.6 \pm 7.1^{*}$ & $46.6 \pm 10.3^{*}$ & $23.5 \pm 5.7^{*}$ & $11.3 \pm 3.2$ \\
\hline MCs-1 group & $10.8 \pm 3.1$ & $22.5 \pm 3.8^{*}$ & $45.1 \pm 8.6^{*}$ & $56.1 \pm 9.2^{*}$ & $33.6 \pm 6.8^{*}$ & $15.6 \pm 5.9$ \\
\hline MCs-2 group & $10.3 \pm 2.6$ & $20.3 \pm 2.9^{*}$ & $43.9 \pm 5.8^{*}$ & $52.8 \pm 7.2^{*}$ & $28.6 \pm 7.1^{*}$ & $13.2 \pm 6.7$ \\
\hline
\end{tabular}

* Significant difference compared with the preoperative in each group. 
Table 3 Comparison of preoperative, postoperative and the final follow-up radiographic parameters in the 3 groups

\begin{tabular}{cllll}
\hline & MCs-0 group & MCs-1 group & MCs-2 group & $\boldsymbol{P}$ value \\
\hline Preoperative & & & & \\
$\mathrm{DH}(\mathrm{mm})$ & $9.7 \pm 1.5$ & $8.9 \pm 2.1$ & $8.7 \pm 1.6$ & 0.013 \\
$\mathrm{LL}\left({ }^{\circ}\right)$ & $50.1 \pm 9.5$ & $49.6 \pm 10.5$ & $50.3 \pm 10.5$ & 0.631 \\
$\mathrm{SL}\left({ }^{\circ}\right)$ & $16.3 \pm 7.2$ & $15.7 \pm 6.2$ & $15.8 \pm 7.5$ & 0.199 \\
Postoperative & & & \\
$\mathrm{DH}(\mathrm{mm})$ & $11.5 \pm 1.9^{*}$ & $11.3 \pm 2.1^{*}$ & $11.6 \pm 1.7^{*}$ & 0.484 \\
$\mathrm{LL}\left({ }^{\circ}\right)$ & $54.3 \pm 10.8^{*}$ & $55.8 \pm 11.3^{*}$ & $54.5 \pm 13.6^{*}$ & 0.456 \\
$\mathrm{SL}\left({ }^{\circ}\right)$ & $18.9 \pm 6.3^{*}$ & $18.2 \pm 7.8^{*}$ & $18.5 \pm 8.3^{*}$ & 0.601 \\
Final follow-up & & & \\
$\mathrm{DH}(\mathrm{mm})$ & $10.9 \pm 2.1^{*}$ & $9.7 \pm 1.5^{*}$ & $9.8 \pm 1.6^{*}$ & 0.027 \\
$\mathrm{LL}\left({ }^{\circ}\right)$ & $53.5 \pm 11.6^{*}$ & $52.8 \pm 13.3^{*}$ & $52.8 \pm 15.1^{*}$ & 0.693 \\
$\mathrm{SL}\left({ }^{\circ}\right)$ & $18.1 \pm 7.5^{*}$ & $17.3 \pm 6.7^{*}$ & $17.8 \pm 8.7^{*}$ & 0.436 \\
\hline
\end{tabular}

* Significant difference compared with the preoperative in each group.

grafting. It has a good pressure-bearing capacity, reasonable fusion rate, and no rejection reaction. However, it can prolong the operation and increase the recovery time and postoperative pain [28]. Allogeneic freeze-dried bone is made from fresh bone tissue after deep freezing, drying, and gamma radiation sterilization. Its processing, sterilization, and preservation techniques are gradually becoming mature and increasingly being applied. It is the most widely used bone graft material in China and overseas in recent years. The use of allogeneic freezedried bone graft precludes the problems of limited autologous bone supply and does not entail invasive bone extraction. Numerous studies have confirmed that homogeneous freeze-dried bone exhibits strong osteoconductivity and is a relatively ideal material or cell carrier for bone defect repair, in addition to retaining some of its biologically active osteoinductive components [29, 30]. However, it still has some shortcomings compared with autologous bone graft; these include the risk of immune rejection, inflammatory reactions, reduced osteoinductive activity, decreased mechanical strength after long-term preservation, high incidence of bone resorption, and poor loading capacity.

Postoperative CRP and ESR levels are routinely monitored to detect postoperative inflammation and infection. In this study, the CRP levels were elevated earlier than ESR values, peaked on the third day after surgery, and returned to normal levels around the fifteenth day. The ESR levels reached their peak on the seventh day and returned to normal around the twenty-first postoperative day. The CRP level was a more sensitive index compared with the ESR. However, the trends of CRP and ESR levels were similar in the three groups. The CRP and ESR levels in the MCs-1 and MCs-2 groups were significantly higher than those in the MCs- 0 group. However, there were no significant differences between the MCs-1 and MCs-2 groups in this respect.

Previous studies have found no significant difference in the fusion rate achieved with the use of autologous iliac bone graft and autologous local bone graft for lumbar fusion surgery. However, no studies have compared the fusion rate in the context of use of autologous local bone graft and allogeneic freeze-dried bone graft. In previous studies, the amount of bone graft showed a positive correlation with the fusion rate of the bone graft $[25,27,31]$. Use of allogeneic freeze-dried bone as a supplement for autologous local bone graft has some theoretical advantages in that it provides a larger bone volume and a higher proportion of cancellous bone. In the present study, to avoid mechanical instability due to excessive bone removal by decompression, we performed expanded "windowing" decompression of the vertebral lamina. Therefore, the amount of bone graft during intervertebral fusion was often insufficient, and was supplemented with an allogeneic bone graft. Thus, allogeneic freeze-dried bone graft plus autologous local bone graft was used to ensure sufficient bone volume.

MCs-1 represent an active and inflammatory phase of the endplate. During the surgery, a large discectomy

Table 4 Comparison of preoperative, postoperative and final follow-up clinical outcomes in the 3 groups

\begin{tabular}{|c|c|c|c|c|}
\hline & MCs-0 group & MCs-1 group & MCs-2 group & $P$ value \\
\hline \multicolumn{5}{|l|}{ ODI } \\
\hline Preoperative & $25.3 \pm 8.8$ & $26.7 \pm 9.3$ & $28.2 \pm 8.5$ & 0.257 \\
\hline Final follow-up & $12.6 \pm 10.3^{*}$ & $8.8 \pm 10.3^{*}$ & $13.6 \pm 9.8^{*}$ & 0.459 \\
\hline \multicolumn{5}{|c|}{ VAS for low back pain } \\
\hline Preoperative & $6.4 \pm 2.7$ & $7.6 \pm 2.5$ & $6.9 \pm 3.2$ & 0.153 \\
\hline Final follow-up & $2.6 \pm 1.9^{*}$ & $1.6 \pm 1.5^{*}$ & $2.5 \pm 1.7^{*}$ & 0.031 \\
\hline \multicolumn{5}{|l|}{ VAS for leg pain } \\
\hline Preoperative & $6.3 \pm 2.8$ & $6.2 \pm 3.6$ & $6.0 \pm 2.2$ & 0.582 \\
\hline Final follow-up & $2.3 \pm 2.1^{*}$ & $2.1 \pm 1.9^{*}$ & $2.7 \pm 1.9^{*}$ & 0.183 \\
\hline
\end{tabular}

* Significant difference compared with the preoperative in each group. 
could result in removal of the inflamed endplate and induce various inflammatory factors, which may be the reason for the relief of low back pain. Subsequently, the lumbar stability was reestablished by internal fixation and bone graft fusion, thus alleviating further damage to the endplate. All patients in this study underwent TLIF. After scraping off the endplate, a PEEK cage of the appropriate size packed with autologous bone graft was placed in the intervertebral space. All the three groups achieved fusion grade 1 or 2 at the most recent followup with satisfactory results. Although there was a loss of intervertebral height at the last follow-up, it was still higher than the preoperative level and did not affect the quality of life, which may be due to a less degree of subsidence.

The risk factors for intervertebral infusion or CS include damage of endplate, osteoporosis, graft type, number of fused segments, and over distraction of intervertebral height. Kwon et al. conducted follow-up of 351 patients for 3 years and found that the clinical outcomes and bony fusion rates were significantly lower in patients with MCs [17]. Cao et al. demonstrated PLIF as a reliable treatment for patients with MCs and predominant low back pain [32]. In this study, there were no significant differences between the three groups in terms of operative time, intraoperative blood loss, or complications, indicating that the surgical difficulty of the three implant fusion modalities was comparable. In the present study, the incidence of subsidence was $40 \%$ in the MCs-1 group, which further confirmed that the endplate is closely related to CS and fusion. The CS rate in the MCs-1 group was significantly higher than that in the MCs-0 group or MCs- 2 group. The CS rate in the MCs-2 group was slightly higher than that in the MCs-0 group, indicating that MCs affect fusion. The damage of endplate can reduce the load-bearing capacity of the endplate and cause CS. The microenvironmental alterations caused by MCs affect the nutrient supply to the endplate. This weakens the endplate strength. This explains the higher rate of CS in the MCs- 1 group as compared with that in the MCs- 0 and MCs- 2 groups.

We believe that careful intraoperative manipulation is essential to achieve successful fusion and reduce CS. The authors recommend scraping the cartilage endplate to remove part of the lesion during surgery and cleaning the endplate so that it oozes a small amount of blood; this can promote blood supply in the bone graft area and facilitate fusion. Preserving the intact bony endplate and preventing damage to the endplate may help avoid settling of the fusion apparatus. To ensure the amount of bone graft, allograft bone can be used to promote fusion, and a suitable intervertebral cage can be selected to avoid over distracting the intervertebral height and cause damage to the endplate. On the other hand, to improve the longitudinal support of the intervertebral bone graft, large pieces of decompression bone were preserved as much as possible during decompression, especially in the early stage of decompression. The inferior articular process in the surgical space was removed by chiseling with a bone knife, and the whole piece was trimmed and implanted into the surgical space to provide sufficient longitudinal support and reduce the loss of distant correction. To achieve successful fusion, the cartilage should be removed from the surface without causing injury to the subchondral trabecular bone. Failure of the subchondral trabecular bone to support the compressive load between the intervertebral graft and vertebrae during graft incorporation may cause loss of the disc space restoration or graft subsidence/nonunion/failure [3335].

\section{Limitations}

Some limitations of this study should be considered while interpreting the results. First, we did not evaluate the status of the endplate during the surgery, which may influence the fusion. Some patients underwent rehabilitation exercises at other institutions, which could not be accurately controlled for in the analysis. Second, the small sample size and retrospective nature of the study made it difficult to manifest all types of MCs, and to exclude the possibility of selection bias. Due to the natural distribution characteristics of MCs, none of the patients in our cohort had MCs-3. Third, there was a lack of postoperative MRI data; thus, potential change in the type of MCs could not be determined. Furthermore, it is believed that no substitutable grafts can achieve excellent fusion rate, or exhibit biocompatibility and osteoconductivity comparable to that of autologous bone. Our results need to be further confirmed by long-term follow-up and a larger randomized controlled study.

\section{Conclusion}

In this study, MCs had no impact on fusion rates and clinical outcomes after TLIF with the hybrid graft (autologous local bone graft and allogeneic freeze-dried bone graft). However, MCs-1 increased the risk of cage subsidence and showed superior outcomes in terms of low back pain.

\footnotetext{
Abbreviations

TLIF: Transforaminal lumbar interbody fusion; CS: Cage subsidence; DH: DisC height; SL: Segmental lordosis; MCs: Modic changes; MRI: Magnetic resonance imaging; LDH: Lumbar disc herniation; LSS: Lumbar spinal stenosis; LS: Lumbar spondylolisthesis; CRP: C-reactive protein; ESR: Erythrocyte sedimentation rate; ODI: Oswestry Disability Index; VAS: Visual analog scale
}

Acknowledgements Not applicable 


\section{Authors' contributions}

JJ carried out the manuscript preparation and experimental design. $J L$ conducted patient visits and statistical analysis of the data. YL carried out statistical analysis of data. WZ revised the manuscript critically for important intellectual content and gave final approval of the version to be published. The authors read and approved the final version of this manuscript.

\section{Funding}

There was no direct funding source aligned to this study.

\section{Availability of data and materials}

Not applicable

\section{Ethics approval and consent to participate}

The Ethics Committee of Third Hospital of Hebei Medical University approved this study. Patient consent for review of medical records was not required, as all data were de-identified. All protocols were conducted in accordance with the research principles in the Declaration of Helsinki.

\section{Consent for publication}

Not applicable

\section{Competing interests}

This material has not been published and is not under consideration elsewhere. The authors declare that they have no competing interests.

\section{Author details}

'Department of Spinal Surgery, The Third Hospital of Hebei Medical University, Shijiazhuang 050051, People's Republic of China. ${ }^{2}$ Department of Spinal Surgery, Harrison International Peace Hospital, Hengshui 053000, Hebie, People's Republic of China. ${ }^{3} T$ The Key Laboratory of Orthopedic Biomechanics of Hebei Province, The Third Hospital of Hebei Medical University, Shijiazhuang 050051, People's Republic of China.

\section{Received: 9 June 2021 Accepted: 5 August 2021}

\section{Published online: 11 August 2021}

\section{References}

1. Mobbs RJ, Phan K, Malham G, Seex K, Rao PJ. Lumbar interbody fusion: techniques, indications and comparison of interbody fusion options including PLIF, TLIF, MI-TLIF, OLIF/ATP. LLIF and ALIF. J Spine Surg. 2015;1 (1): 2-18. https://doi.org/10.3978/j.jssn.2414-469X.2015.10.05.

2. de Kunder SL, van Kuijk SMJ, Rijkers K, Caelers IJMH, van Hemert WLW, de Bie RA, et al. Transforaminal lumbar interbody fusion (TLIF) versus posterio lumbar interbody fusion (PLIF) in lumbar spondylolisthesis: a systematic review and meta-analysis. Spine J. 2017;17(11):1712-21. https://doi.org/10.1 016/j.spinee.2017.06.018.

3. Reid PC, Morr S, Kaiser MG. State of the union: a review of lumbar fusion indications and techniques for degenerative spine disease. J Neurosurg Spine. 2019:31(1):1-14. https://doi.org/10.3171/2019.4.SPINE18915.

4. Parajón A, Alimi M, Navarro-Ramirez R, Christos P, Torres-Campa JM, Moriguchi $Y$, et al. Minimally invasive transforaminal lumbar interbody fusion: meta-analysis of the fusion rates. What is the optimal graft material? Neurosurgery. 2017:81(6):958-71. https://doi.org/10.1093/neuros/nyx141.

5. Rihn JA, Kirkpatrick K, Albert TJ. Graft options in posterolateral and posterior interbody lumbar fusion. Spine (Phila Pa 1976). 2010;35(17):1629-39. https:// doi.org/10.1097/BRS.0b013e3181d25803.

6. Yao YC, Lin HH, Chou PH, Wang ST, Chang MC. Differences in the interbody bone graft area and fusion rate between minimally invasive and traditional open transforaminal lumbar interbody fusion: a retrospective short-term image analysis. Eur Spine J. 2019;28(9):2095-102. https://doi.org/10.1007/ s00586-019-06002-4

7. Yuan W, Kaliya-Perumal AK, Chou SM, Oh JY. Does lumbar interbody cage size influence subsidence? A biomechanical study. Spine (Phila Pa 1976). 2020;45(2):88-95. https://doi.org/10.1097/BRS.0000000000003194.

8. Yao YC, Chou PH, Lin HH, Wang ST, Liu CL, Chang MC. Risk factors of cage subsidence in patients received minimally invasive transforaminal lumbar interbody fusion. Spine (Phila Pa 1976). 2020;45(19):E1279-85. https://doi org/10.1097/BRS.0000000000003557.

9. Kim MC, Chung HT, Cho IL, Kim DJ, Chung NS. Subsidence of polyetheretherketone cage after minimally invasive transforaminal lumbar interbody fusion. J Spinal Disord Tech. 2013;26(2):87-92. https://doi.org/10.1 097/BSD.0b013e318237b9b1.

10. Oh KW, Lee JH, Lee JH, Lee DY, Shim HJ. The correlation between cage subsidence, bone mineral density, and clinical results in posterior lumbar interbody fusion. Clin Spine Surg. 2017;30(6):E683-9. https://doi.org/10.1097/ BSD.0000000000000315.

11. Liu J, Ding W, Yang D, Wu H, Hao L, Hu Z, et al. Modic changes (MCs) associated with endplate sclerosis can prevent cage subsidence in oblique lumbar interbody fusion (OLIF) stand-alone. World Neurosurg. 2020;138: e160-8. https://doi.org/10.1016/j.wneu.2020.02.047.

12. Dudli S, Sing DC, Hu SS, Berven SH, Burch S, Deviren V, et al. ISSLS PRIZE IN BASIC SCIENCE 2017: Intervertebral disc/bone marrow cross-talk with Modic changes. Eur Spine J. 2017;26(5):1362-73. https://doi.org/10.1007/s00586-01 7-4955-4.

13. Dudli S, Fields AJ, Samartzis D, Karppinen J, Lotz JC. Pathobiology of Modic changes. Eur Spine J. 2016;25(11):3723-34. https://doi.org/10.1007/s00586-01 6-4459-7.

14. Modic MT, Steinberg PM, Ross JS, Masaryk TJ, Carter JR. Degenerative disk disease: assessment of changes in vertebral body marrow with MR imaging Radiology. 1988;166(1 Pt 1):193-9. https://doi.org/10.1148/radiology.1 66.1.3336678.

15. Kim SM, Rhee W, Ha S, Lim JH, Jang IT. Influence of alendronate and endplate degeneration to single level posterior lumbar spinal interbody fusion. Korean J Spine. 2014;11(4):221-6. https://doi.org/10.14245/kjs.2 014.11.4.221.

16. Liu HY, Zhou J, Wang B, Wang HM, Jin ZH, Zhu ZQ, et al. Comparison of topping-off and posterior lumbar interbody fusion surgery in lumbar degenerative disease: a retrospective study. Chin Med J (Engl). 2012;125(22): 3942-6.

17. Kwon YM, Chin DK, Jin BH, Kim KS, Cho YE, Kuh SU. Long term efficacy of posterior lumbar interbody fusion with standard cages alone in lumbar disc diseases combined with Modic changes. J Korean Neurosurg Soc. 2009; 46(4):322-7. https://doi.org/10.3340/jkns.2009.46.4.322.

18. Bridwell KH, Lenke LG, McEnery KW, Baldus C, Blanke K. Anterior fresh frozen structural allografts in the thoracic and lumbar spine. Do they work if combined with posterior fusion and instrumentation in adult patients with kyphosis or anterior column defects. Spine (Phila Pa 1976). 1995;20(12): $1410-8$.

19. Buser Z, Brodke DS, Youssef JA, Meisel HJ, Myhre SL, Hashimoto R, et al. Synthetic bone graft versus autograft or allograft for spinal fusion: a systematic review. J Neurosurg Spine. 2016t;25(4):509-16. https://doi.org/1 0.3171/2016.1.SPINE151005.

20. Axelsen MG, Overgaard S, Jespersen SM, Ding M. Comparison of synthetic bone graft ABM/P-15 and allograft on uninstrumented posterior lumbar spine fusion in sheep. J Orthop Surg Res. 2019;14(1):2. https://doi.org/10.11 86/s13018-018-1042-4

21. Morris MT, Tarpada SP, Cho W. Bone graft materials for posterolateral fusion made simple: a systematic review. Eur Spine J. 2018;27(8):1856-67. https:// doi.org/10.1007/s00586-018-5511-6.

22. vonder Hoeh $\mathrm{NH}$, Voelker $\mathrm{A}$, Heyde CE. Results of lumbar spondylodeses using different bone grafting materials after transforaminal lumbar interbody fusion (TLIF). Eur Spine J. 2017;26(11):2835-42. https://doi.org/10.1 007/s00586-017-5145-0.

23. Lechner R, Putzer D, Liebensteiner M, Bach C, Thaler M. Fusion rate and clinical outcome in anterior lumbar interbody fusion with beta-tricalcium phosphate and bone marrow aspirate as a bone graft substitute. A prospective clinical study in fifty patients. Int Orthop. 2017;41(2):333-9. https://doi.org/10.1007/s00264-016-3297-x.

24. Kaiser MG, Groff MW, Watters WC 3rd, Ghogawala Z, Mummaneni PV, Dailey AT, et al. Guideline update for the performance of fusion procedures for degenerative disease of the lumbar spine. Part 16: bone graft extenders and substitutes as an adjunct for lumbar fusion. J Neurosurg Spine. 2014;21(1): 106-32. https://doi.org/10.3171/2014.4.SPINE14325.

25. Ito Z, Matsuyama Y, Sakai Y, Imagama S, Wakao N, Ando K, et al. Bone union rate with autologous iliac bone versus local bone graft in posterior lumbar interbody fusion. Spine (Phila Pa 1976). 2010:35(21):E1101-5. https://doi. org/10.1097/BRS.0b013e3181de4f2e.

26. Ido K, Asada Y, Sakamoto T, Hayashi R, Kuriyama S. Use of an autologous cortical bone graft sandwiched between two intervertebral spacers in posterior lumbar interbody fusion. Neurosurg Rev. 2001;24(2-3):119-22. https://doi.org/10.1007/PL00012394. 
27. Ito Z, Imagama S, Kanemura T, Hachiya Y, Miura Y, Kamiya M, et al. Bone union rate with autologous iliac bone versus local bone graft in posterior lumbar interbody fusion (PLIF): a multicenter study. Eur Spine J. 2013;22(5): 1158-63. https://doi.org/10.1007/s00586-012-2593-4.

28. Trouillier H, Birkenmaier C, Rauch A, Weiler C, Kauschke T, Refior HJ. Posterior lumbar interbody fusion (PLIF) with cages and local bone graft in the treatment of spinal stenosis. Acta Orthop Belg. 2006;72(4):460-6.

29. Vaz K, Verma K, Protopsaltis T, Schwab F, Lonner B, Errico T. Bone grafting options for lumbar spine surgery: a review examining clinical efficacy and complications. SAS J. 2010;4(3):75-86. https://doi.org/10.1016/j.esas.2010.01. 004.

30. Martin GJ Jr, Haid RW Jr, MacMillan M, Rodts GE Jr, Berkman R. Anterior cervical discectomy with freeze-dried fibula allograft. Overview of 317 cases and literature review. Spine (Phila Pa 1976). 1999;24(9):852-8.

31. Park JB, Yang JH, Chang DG, Suk SI, Suh SW, Kim GU, et al. Comparison of union rates between autogenous iliac crest bone graft and local bone graft as fusion materials in lumbar fusion surgery: an evaluation of up to 3-level fusion. World Neurosurg. 2020;139:e286-92. https://doi.org/10.1016/j.wneu.2 020.03.211.

32. Cao $P$, Chen Z, Zheng Y, Wang Y, Jiang L, Yang Y, et al. Comparison of simple discectomy and instrumented posterior lumbar interbody fusion for treatment of lumbar disc herniation combined with Modic endplate changes. Chin Med J (Engl). 2014;127(15):2789-94.

33. Park MK, Kim KT, Bang WS, Cho DC, Sung JK, Lee YS, et al. Risk factors for cage migration and cage retropulsion following transforaminal lumbar interbody fusion. Spine J. 2019;19(3):437-47. https://doi.org/10.1016/j. spinee.2018.08.007.

34. Lee DY, Park YJ, Song SY, Jeong ST, Kim DH. Risk factors for posterior cage migration after lumbar interbody fusion surgery. Asian Spine J. 2018;12(1): 59-68. https://doi.org/10.4184/asj.2018.12.1.59.

35. Pan FM, Wang SJ, Yong ZY, Liu XM, Huang YF, Wu DS. Risk factors for cage retropulsion after lumbar interbody fusion surgery: series of cases and literature review. Int J Surg. 2016;30:56-62. https://doi.org/10.1016/j.jjsu.2016. 04.025 .

\section{Publisher's Note}

Springer Nature remains neutral with regard to jurisdictional claims in published maps and institutional affiliations.

\section{Ready to submit your research? Choose BMC and benefit from:}

- fast, convenient online submission

- thorough peer review by experienced researchers in your field

- rapid publication on acceptance

- support for research data, including large and complex data types

- gold Open Access which fosters wider collaboration and increased citations

- maximum visibility for your research: over $100 \mathrm{M}$ website views per year

At $\mathrm{BMC}$, research is always in progress.

Learn more biomedcentral.com/submissions 